\title{
Ainda usamos carvão!
}

\author{
We are still using coal!
}

\begin{abstract}
Luciana Nemer Diniz
Doutora Professora Associada IV, Departamento de Arquitetura e Pós Graduação em Arquitetura e Urbanismo, Universidade Federal Fluminense, Niterói, Brasil. luciana_nemer@ig.com.br
\end{abstract}

\section{Philipe Lopes Cantreva}

Graduando de Arquitetura e Urbanismo, Escola de Arquitetura e Urbanismo, Universidade Federal Fluminense, Niterói, Brasil. pcantreva@id.uff.br

\section{Carolline Amaral}

Arquiteta e Urbanista, Escola de Arquitetura e Urbanismo, Universidade Federal Fluminense, Niterói, Brasil. carollineamaral@id.uff.br

\section{RESUMO}

0 presente trabalho visa discursar sobre o carvão como meio de expressão visual aplicado ao ensino de desenho, trazendo a temática das representações tradicionais como métodos de elaboração visuais ainda interessantes para a formação profissional de arquitetos e urbanistas em um ambiente cada vez mais digital. Exploram-se as qualidades expressivas e técnicas do material carvão em seus diversos estilos tendo maior enfoque em suas possibilidades pictóricas como a técnica do tom, buscando assim a formação das capacidades artísticas e criativas de estudantes e profissionais de arquitetura e urbanismo. Baseando-se em trabalhos realizados em ambiente acadêmico, pela experiência pedagógica proporcionada pelo ensino da técnica em aula e complementada pela pesquisa bibliográfica em diversos textos da área, o artigo demostra as diversas possibilidades e oportunidades do uso do material.

\section{Palavras-chave: carvão; pintura; representação}

\section{ABSTRACT}

The present work aims to address the coal as a means of visual expression applied to teaching drawing, bringing themes of traditional representations as methods of visual elaborations still interesting for the professional training of architects and urban planners in an increasingly digital environment. It explores the expressive and technical qualities of the coal in its various styles, with a greater focus on its pictorial possibilities as tone technique, for the artistic and creative capacities of students and professionals of architecture and urbanism. Based on works carried out in an academic environment and by the pedagogical experience provided by the teaching of the technique in class and complemented by the bibliographical research in several texts of the area, the article shows the various possibilities and opportunities of the use of the material.

Keywords:coal; painting; representation 


\section{INTRODUÇÃO}

Frente ao grande movimento tecnológico vivido no século XXI, habilidades que anteriormente eram valorizadas estão se perdendo com o decorrer do tempo, entre elas o desenho a carvão.

Considerado uma ferramenta clássica no que se refere à ilustração, a utilização do carvão na arte é muito difundida. "O carvão é a técnica de desenho mais antiga que se conhece e, ao mesmo tempo, a mais simples." (GOUVEIA, 2019, p. 01).

0 projeto de monitoria da EAU (Escola de Arquitetura e Urbanismo) da UFF (Universidade Federal Fluminense) tem consistido em uma oportunidade no desenvolvimento de trabalhos acadêmicos, conciliando a análise teórica e prática de diversos temas com a experiência pedagógica em sala de aula. Os produtos gerados em tais projetos têm contribuído para constante evolução da qualidade de ensino e tem sido de uso para novos estudantes.

O Estudo do Carvão e sua Aplicação na Expressão - apostila de auxílio para a disciplina de Expressão Gráfica da EAU-UFF, feita como projeto de Monitoria pela aluna Carolline Amaral no ano de 2011, é desde então base para a utilização do carvão nos trabalhos realizados em aula. 0 tema evidencia a significância do material em suas diversas formas para a expressão e representação gráfica, sendo historicamente utilizado como um meio de exposição de ideias na arquitetura.

0 trabalho põe-se como pedra fundamental da realização do atual artigo, como ponto de partida para a elaboração de uma investigação sobre as importâncias do material, como meio para desenho no desenvolvimento na parte criativa de projetos de arquitetura (libertando os traços) e tendo enfoque na sua importância pedagógica no ambiente universitário.

Neste sentido, parte-se com o princípio da fundamental importância de existir no repertório profissional do arquiteto e urbanista a capacidade de se expressar graficamente, característica compartilhada por designers de moda, de produto, artistas gráficos e ilustradores. É coerente dispor deste modo, de disciplinas de expressão gráfica durante a formação acadêmica, onde a aprendizagem de um conjunto de técnicas amplia o potencial de comunicação de ideias e conceitos através de desenhos e outras composições visuais.

A metodologia para o presente artigo se pautou em pesquisa bibliográfica para buscar o estado da arte no assunto em trabalhos científicos e demais publicações. Quanto aos procedimentos técnicos foram feitas consultas em fontes secundárias, material já publicado (livros, monografias e dissertações, sites governamentais e sites de artistas que compartilham suas experiências com a técnica).

A segunda etapa da pesquisa ocorreu sobre os registros obtidos a partir de fontes primárias, ou seja, material coletado em sala de aula e no 
laboratório do Grupo de Pesquisa Análise e Representação da Forma. Dando prosseguimento à pesquisa, o estudo realizado em 2011 foi resgatado assim como os trabalhos realizados com a técnica do carvão; a estes, se dedicou um olhar especial ao examiná-los, escaneá-los e analisá-los.

O carvão é um material usado desde a antiguidade e pode ser listado entre os primeiros utilizados pelo homem. 0 desenho com carvão é um dos meios mais antigos de expressão visual do homem, presente em civilizações ancestrais.

\begin{abstract}
Conforme Gonçalves, Niéde Guidon, em 1971, na serra da Capivara, Piauí anunciou a descoberta de vestígios de carvão de uma suposta fogueira datada de 40.000 anos, sendo assim, os primeiros grupos teriam, há pelo menos 70.000 anos, adentrado a América pelo Estreito de Bering. Essa teoria tem sido pesquisada seriamente pela comunidade científica de arqueologia, recebendo adesões de importantes arqueólogos (GONÇALVES, 2019, p. 06).
\end{abstract}

Segundo Frenhi durante a renascença, nos desenhos feitos nas paredes das igrejas, utilizava-se a técnica de pintura com carvão por meio de moldes vazados onde o material era aplicado (FRENHI, 2010, p. 01).

Mas, apesar de sua longa e importante história, ele é visto ainda com reservas por muitos artistas - e seu uso acaba ficando restrito a esboços preparatórios para pintura a óleo.

$\mathrm{Na}$ verdade, o carvão possibilita resultados muito expressivos. 0 material desliza sobre o papel com um toque agradável e basta uma leve variação na pressão para obter grande variedade de efeitos, desde os delicados tons médios texturizados até os escuros profundos. As possibilidades são muitas, de esfumá-lo a misturá-lo com o dedo ou um esfuminho e produzir luzes, removendo-o com um limpa-tipos. Por esta razão, o carvão é excelente para expressar com eficácia o jogo de luzes e sombras, as formas e os volumes e pode ser adquirido em diversos formatos.

\begin{abstract}
No mercado, o carvão é oferecido sob diversas formas, sendo a mais comum o bastão (de carvão vegetal natural de videira ou de salgueiro). Há também os bastões chatos de carvão, mais comprimidos, próprios para cobrir grandes áreas, e os lápis de carvão ou em pó. Estes são os melhores instrumentos para desenhos detalhados, pois se pode apontá-los bem finos. Existem diferentes qualidades de lápis de carvão, de duros a macios, e diversos tipos de bastão (FERRARI, 1985, p. 406).
\end{abstract}

Degas, Corot e Pissarro são alguns dos grandes artistas que adotaram a técnica do carvão. Edgar Degas, famoso pela pintura de bailarinas, esboçava seus desenhos, assim como finalizava diversas gravuras em carvão. No site Pinterest encontram-se 43 imagens de Corot e boa parte delas a carvão (OHNO, 2019, p. 01). Camille Pissarro, mestre francês impressionista, veio a influenciar a obra de Van Gohg. Ambos eram apreciadores de croquis e desenhos finalizados a carvão.

Em janeiro de 1879, Van Gohg começa a trabalhar, atuando como pastor na Bélgica, em uma cidadezinha chamada Borinage. 
Impressionado com as condições de miserabilidade dos mineiros nas minas de carvão, elabora vários desenhos inspirados na vida desses mineiros (CARVALHO, 2009, p. 30).

De acordo com San Francisco, o pintor muitas vezes se desesperou com a nova técnica, até que, em 1883, incentivado pela encomenda seu tio Cornelis (desenhos de 12 paisagens de Haia), passa a utilizar o carvão molhado em água e azeite para fixar a pintura, deixando o negro mais cálido e mais profundo (SAN FRANCISCO, 2019, p. 04).

\section{0 CARVÃo}

O carvão mineral é um combustível formado a partir da fossilização de materiais orgânicos, principalmente madeira. No site da Universidade de São Paulo (USP) se tem a seguinte definição: é um combustível formado por meio de processo natural, como a decomposição de organismos mortos soterrados (UNIVERSIDADE DE SÃO PAULO, 2019, p. 01). Ele é encontrado em jazidas localizadas no subsolo terrestre e extraído pelo sistema de mineração.

Para Faria, composto basicamente por carbono e magnésio na forma de betumes, o carvão mineral é uma pedra que apresenta uma cor preta ou marrom escuro, e acredita-se, seja o combustível natural mais abundante do planeta (FARIA, 2006, p. 01). O tempo e a pressão da terra que foi se acumulando sobre o material transformaram-no em uma massa negra homogênea - as jazidas de carvão (UNIVERSIDADE DE SÃO PAULO, 2019, p. 01).

"O carvão mineral é uma mistura de hidrocarbonetos formada pela decomposição de matéria orgânica durante milhões de anos, sob determinadas condições de temperatura e pressão." (RIO GRANDE DO SUL, 2019, p. 172).

O grau de carbonificação destes combustíveis será determinado pelos seguintes fatores externos: pressão, temperatura, placa tectônica e tempo de exposição. Conforme o Departamento de Minas e Energia os carvões da Região Sul são de baixo grau de carbonificação denominados comercialmente como alto-voláteis (RIO GRANDE DO SUL, 2019, p. 201).

Figura 1: Carvão

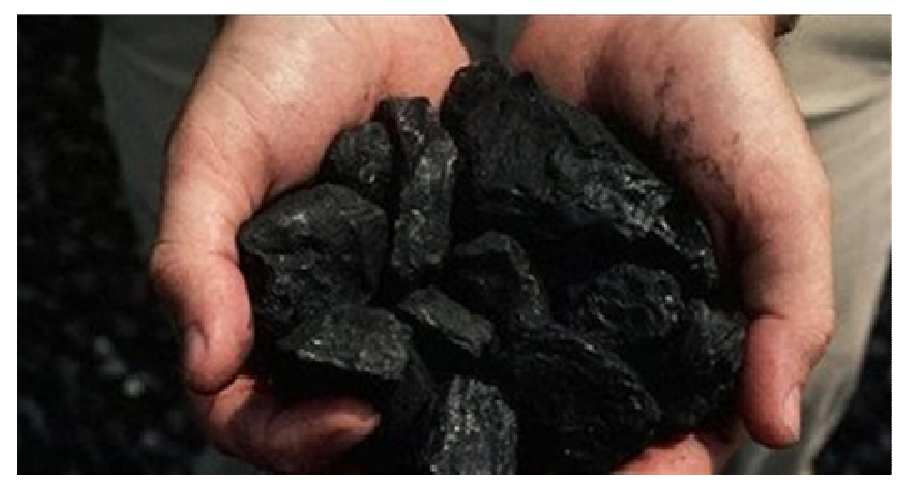

Fonte: https://brasilescola.uol.com.br/geografia/carvao-vegetal.htm(2019). 
A Figura 1 é a lustração do material em sua forma natural.

O Carvão vegetal, também possui cor preta, é obtido pela carbonização da madeira. Informa Brito que o carvão vegetal é obtido na pirólise mediante a ação do calor que elimina a maior parte dos componentes voláteis da madeira - "destilação seca da madeira” (BRITO, 1990, p. 2).

Na Figura 2 é possível observar quatro tipos de carvão: turfa, hulha, lignite e antracite. Estes se distinguem pela sua composição e o seu diferente poder calorífico. Quando a madeira é queimada a $400^{\circ} \mathrm{C}$ de temperatura obtêm-se o carvão vegetal.

Figura 2: Tipos de Carvão
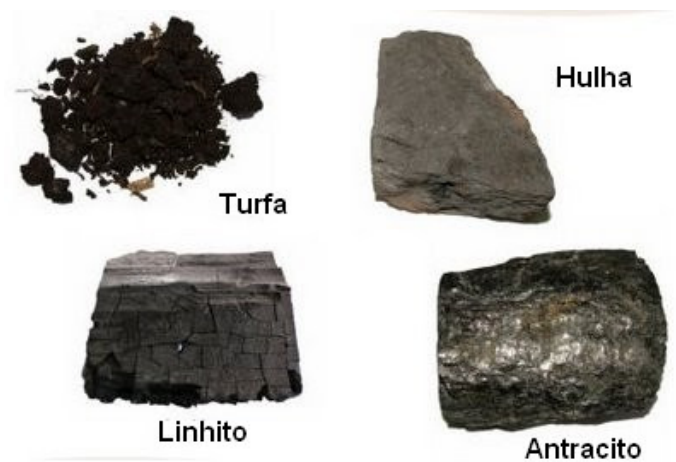

Fonte: http://hulha-eteot.blogspot.com/2011/04/diferencas-entre-os-tipos-decarvao.html(2019).

De acordo descrição fornecida pela USP, com a maior ou menor intensidade da carbonização, o carvão mineral pode ser classificado como linhito, carvão betuminoso e sub-betuminoso (ambos designados como hulha) e antracito (UNIVERSIDADE DE SÃO PAULO, 2019, p. 03). A turfa, na imagem em cima e à esquerda apresenta quantidade de raízes, não tendo a consistência de carvão.

\subsection{Histórico}

0 carvão formou-se principalmente na era primária no período (entre 359 milhões e 245 milhões de anos atrás) quando se formaram importantes jazidas, logo o nome: Idade das Grandes Florestas ou Período Carbonífero (UNIVERSIDADE FEDERAL DE RORAIMA, 2019, p. 01).

Os Romanos, na Grã-Bretanha romana, chegaram a explorar as principais bacias, e grande parte do uso do carvão manteve-se local. No mesmo período, o carvão betuminoso chegou a ser usado para aquecer banhos públicos, banhos em fortes militares e as moradias de indivíduos ricos. Após os romanos deixarem a GrãBretanha, no ano 410, não há registros de utilização do carvão no país até o século XII (DINIZ; AMARAL, 2011, p. 5).

Com a assinatura da Carta Magna, em 1215, o carvão começou a ser comercializado nas áreas da Escócia e no sudeste da Inglaterra Norte. No entanto, não era apropriado para o uso doméstico - lareiras, então, acabou 
sendo utilizado principalmente por artesãos para queima da cal, na metalurgia e na fundição. Em 1228, o carvão foi levado para Londres. Durante o século XIII, o comércio do carvão aumentou consideravelmente na GrãBretanha e até o fim do século a maioria das minas de carvão na Inglaterra, Escócia e País de Gales foram sendo exploradas em pequena escala, e o uso do carvão entre os artesãos se tornou mais difundido.

\begin{abstract}
Durante a primeira metade do século XIV, o carvão começou a ser utilizado no aquecimento doméstico em regiões produtoras de carvão da Inglaterra, já que melhorias foram feitas no projeto de fornos domésticos. Eduardo III foi o primeiro rei a ter interesse no comércio de carvão do nordeste e emitiu mandados para regulamentar o comércio, e permitir a exportação do carvão para Calais. A demanda por carvão aumentou regularmente na GrãBretanha durante o século XV, mas ainda estava sendo usado principalmente nos distritos de mineração, em cidades costeiras ou sendo exportados para a Europa continental. No entanto, como o fornecimento de madeira do século XVI estava começando a falhar na Grã-Bretanha, a utilização do carvão como combustível doméstico expandiu rapidamente (DINIZ; AMARAL, 2011, p. 6).
\end{abstract}

Em 1575, Sir George Bruce Carnock de Culross, na Escócia, abriu a primeira mina de carvão de extração de carvão a partir de um "pit fosso" no fundo do mar na Firth of Forth. Ele construiu uma ilha artificial de carga atrelada a um eixo submerso de 40 pés, que foi conectado a outros dois veios para a drenagem. A tecnologia foi muito além de qualquer método de mineração de carvão no período medieval tardio e foi considerado uma das maravilhas da era industrial.

Devido à sua abundância e seu baixo custo, o carvão foi extraído em várias partes do mundo ao longo da história. Durante a Revolução Industrial se desenvolveu em grande escala, e atualmente, continua a ser uma atividade econômica importante. Comparado aos combustíveis de madeira, o carvão produz uma maior quantidade de energia por unidade de massa e pode ser obtidos em áreas onde a madeira não está prontamente disponível. Embora historicamente utilizado como um meio de aquecimento doméstico, o carvão é agora usado principalmente na indústria, especialmente na fundição e ligas de produção, bem como a geração de eletricidade (DINIZ; AMARAL, 2011, p. 6).

A fumaça do carvão aumentou a poluição em Londres prejudicando a saúde dos habitantes do país. Como resultado disso, uma proclamação real foi emitida em 1306. Em Londres ficou proibida a utilização do carvão, e assim voltaram a utilizar os combustíveis tradicionais como a madeira.

Durante o século XVII uma série de avanços nas técnicas de mineração foram feitas, como o uso de sondagens para encontrar depósitos adequados de bombas de cadeia, impulsionado por rodas d'agua, para drenar as minas de carvão. Depósitos de carvão foram descobertos por colonos no Leste da América do Norte no século XVIII (DINIZ; AMARAL, 2011, p. 8).

0 primeiro uso do carvão conhecido na América foi pelos Astecas que o usavam como combustível e o linhito (Figura 2) como ornamento. 
A Grã-Bretanha desenvolveu as principais técnicas de mineração subterrânea de carvão, no entanto, desde 1890, a mineração do carvão tem sido também uma questão política e social (Figura 3).

Figura 3: Carvoeiras

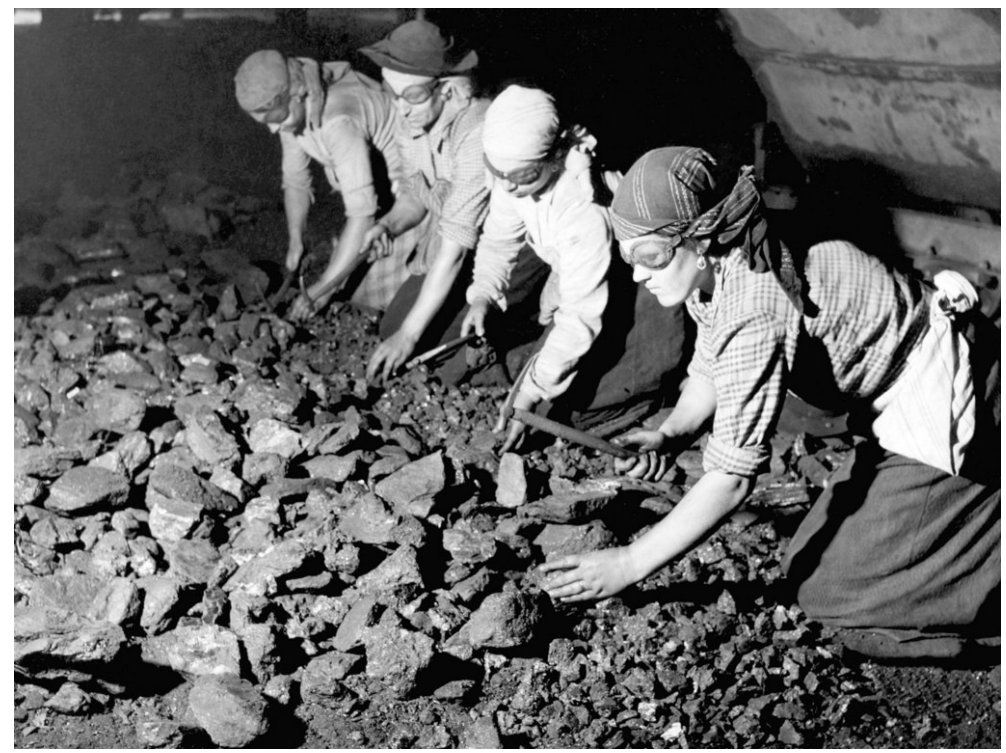

Fonte: https://cadernosdalibania.blogspot.com/2017/04/depois-das-lagrimas-da-minasobram.html (2019).

No século XX, o carvão foi em grande parte substituído nas indústrias, assim como no transporte e utilização doméstica. 0 petróleo e seus combustíveis associados começaram a ser usados como alternativa a partir deste momento. Mineiros de carvão e os sindicatos tornaram-se poderosos em muitos países no século 20, e frequentemente, esses trabalhadores foram os líderes da esquerda ou movimentos socialistas como na Grã-Bretanha, na Alemanha, na Polônia, no Japão, no Canadá e nos EUA. Desde 1970, questões ambientais têm sido levantadas, incluindo a saúde dos mineiros, a destruição da paisagem de minas e remoção do cume, a poluição do ar e da contribuição de combustão de carvão para o aquecimento global.

Os recursos de carvão mineral no Brasil ultrapassam 32 bilhões de toneladas e estão localizados na região coberta por rochas da Bacia do Paraná, no Rio Grande do Sul, Santa Catarina e, subsidiariamente, no Paraná e em São Paulo (RIO GRANDE DO SUL, 2019, p. 188).

A bacia carbonífera catarinense compreende uma faixa de aproximadamente 100 quilômetros de extensão por 25 quilômetros de largura no sul do Estado. Em Santa Catarina é farta a reserva de carvão hulha do tipo sub-betuminoso.

Nos dias atuais o carvão também é usado na medicina, nesse caso chamado de carvão ativado oriundo de determinadas madeiras de aspecto mole e não resinosas. Apesar dos benefícios apresentados com a utilização do carvão vegetal é preciso analisar a consequência que a sua produção provoca. Afirma o autor que 
para o desenvolvimento dessa atividade diversas vezes é preciso retirar a cobertura vegetal de importantes composições vegetativas contidas no território brasileiro, que geralmente não são oriundas de madeiras de reflorestamento ou madeira cultivada para esse fim (FREITAS, 2019, p. 01).

\section{O CARVÃO NA EXPRESSÃO GRÁFICA}

O carvão, um dos meios de desenho mais expressivo tem a sua utilização nos primórdios da civilização humana, sendo o seu registro relacionado às pinturas rupestres. Ainda assim, a imprecisão e a baixa fixação do seu pigmento sempre o associam aos esboços das pinturas a óleo. Apesar dessa característica, é muito utilizado em ateliês de artes visuais e em cursos e faculdades de Arte / Design / Arquitetura pela razão de proporcionar gradações muito vultosas.

0 material se aplica às técnicas conhecidas como do valor ou da tonalidade que, muitas vezes, é erroneamente nomeada como técnica de sombra. Estas tonalidades são obtidas facilmente variando-se a pressão do carvão sobre o papel, que se desprende facilmente com um toque suave, deslizando sobre esse. Por esta característica pode ter sua aparência sobre a base facilmente alterada com materiais específicos como o esfuminho, o limpa-tipos ou até mesmoo algodão, para não dizer das misturas com os dedos da mão do artista.

Para Marivc, nas aulas de desenho e figura humana é um dos materiais mais usados pelas suas ótimas características de riscador, que se deposita suavemente no papel ao sabor dos gestos (MARIVC, 2010, p. 01).

\subsection{Tipos de Carvão para Desenho}

O carvão é encontrado à venda no mercado, em várias durezas e de diversas formas: sob a forma de pequenos galhos carbonizados com o aspecto original, em pó, em barras prismáticas ou cilíndricas regulares e ainda na forma de lápis.

O primeiro - carvão em bastão ou carvão de salgueiro é obtido a partir de galhos da árvore. No comércio na forma de bastões mais finos prestam-se bem para esboços preliminares e trabalhos detalhados ou delicados. Os mais grossos, com diâmetro de até $6 \mathrm{~mm}$, são melhores para cobrir rapidamente grandes áreas com traços fortes e vibrantes.

Segundo Diniz e Amaral quanto mais macio o carvão, mais ele se desfaz em pó e com menos facilidade adere ao papel, ao contrário do carvão comprimido. Portando, este é uma boa escolha para esfumar ou mudar seu desenho, a fim de criar efeitos mais amplos, no entanto, ele suja mais. Para solucionar a questão é preciso utilizá-lo com cuidado e aplicar fixador em spray quando o trabalho estiver pronto. 0 carvão macio produz uma marca negra mais intensa, enquanto os bastões mais duros são bons para os tons de cinza intermediários (DINIZ; AMARAL, 2011, p. 10). Marivc afirma que as 
diversas durezas de carvão estão relacionadas ao tempo de carbonização e devem ser escolhidas em função do tipo de trabalho (MARIVC, 2010, p. 01). A Figura 4 exemplifica os tipos de carvão para desenho, à esquerda acima em bastão em três diferentes espessuras, abaixo destes na forma de lápis, à direita acima em pó e abaixo em barrinhas.

Figura 4: Tipos de Carvão para o Desenho

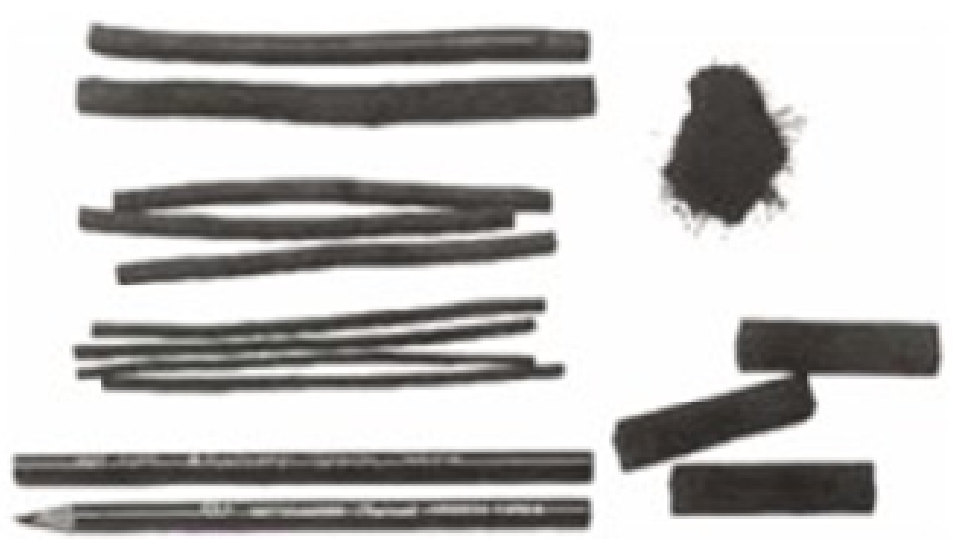

Fonte: MARIVC (2010).

O carvão em pó, geralmente aplicado com o dedo ou com um esfuminho é o ideal para espalhar o produto sobre o papel, quando se trata de cobrir áreas extremamente grandes. Esta forma permite obter grande variedade de efeitos tonais (quanto mais pó, mais escuro o tom). E, caso o desenhista opte por utilizar a ponta do esfuminho, acessório importante na aplicação da técnica, obtem-se resultados muito delicados.

Na forma de lápis, o carvão é verificado no interior de cilindros de madeira em finos bastões comprimidos. A grande vantagem é que são mais fáceis de controlar que o carvão em bastão, produzindo linhas e traços firmes. Sua extremidade é fácil de ser apontada, tornando-o ideal para desenhos detalhados ou muito pequenos. Entretanto, seu envoltório impede que sejam usados para traços largos dificultando a mistura de soluções gráficas. De acordo com Amaral os lápis mais macios produzem marcas tão densas como as do carvão comprimido, permanecendo visíveis mesmo sobre um fundo negro profundo (DINIZ; AMARAL, 2011, p. 10).

0 formato comprimido do material é comercializado em barras de compostas pela combinação do carvão em pó e aglutinante. Trata-se de um tipo mais forte que o comum em bastão e, portanto, mais difícil de quebrar. Entretanto, assim como o lápis, deixa marcas fortes dificultando a tarefa de apagar erros cajo seja necessário. Quando a face da barra é utilizada para o trabalho, a barra de carvão comprimido se torna especialmente útil para preencher grandes áreas de tom. Útil também para reproduzir o efeito de luz forte, como a do sol, já que o carvão comprimido, por ser tão escuro, faz com que as áreas claras fiquem ainda mais intensas. 
Complementa Marivc que em trabalhos com traços mais grossos, ou para obter manchas negras e maiores mais facilmente, se deve utilizar os tipos mais macios e em barras (MARIVC, 2010, p. 01). 0 carvão permite o trabalho com muita facilidade sobre grandes superfícies, no entanto, marca a base com facilidade. Em trabalhos mais lineares, pequenas áreas de desenho ou ainda com mais detalhe deve-se utilizar as formas mais duras do material.

Afirma Marivc que o carvão é também utilizado no esboço de pinturas a óleo, acrílica, de cenários e murais, pois desprende-se com facilidade, deixando apenas suaves traços ou manchas sobre a superfície, servindo de guias no trabalho (MARIVC, 2010, p. 02). Em função desta característica a escolha da base ou superfície de desenho / pintura é fundamental para o bom resultado do trabalho.

\subsection{Superfícies de Desenho}

Desenhos a carvão podem ser feitos em papel branco comum (sulfite), no entanto, uma das características mais interessantes do carvão é que ele tende a revelar a granulação e a textura do papel em que se desenha - o que o torna particularmente expressivo em papéis bem texturizados.

O papel texturizado é especial para o desenho a carvão e oferece bons resultados também com outros instrumentos de desenho como o pastel seco e o lápis. Ele deve apresentar superfície canelada e bastante resistente, para que possa ser rasurada várias vezes. Os papéis de textura áspera têm granulação maior e superfície irregular, o que torna as áreas fundidas mais vívidas e os traços mais acentuados (Figura 5).

Figura 5: Papel Texturizado

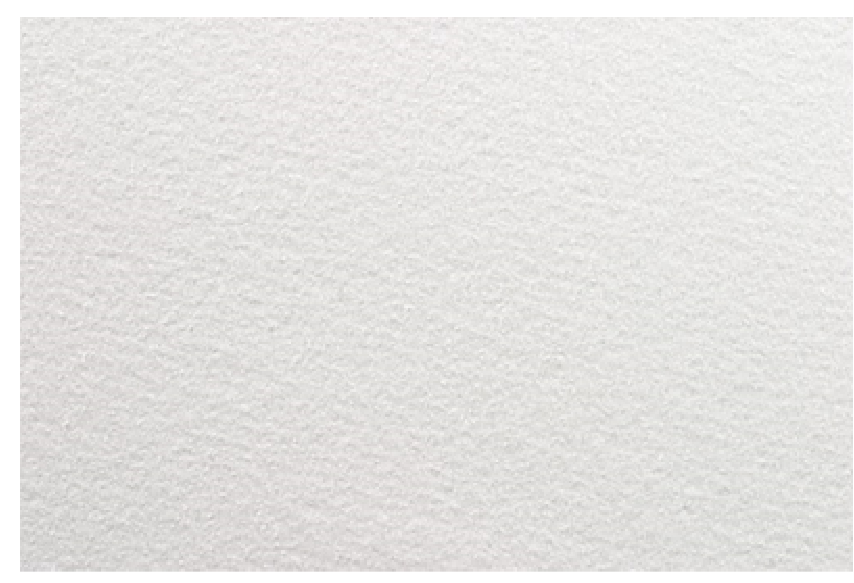

Fonte: DINIZ; AMARAL (2011).

0 mercado oferece diversas marcas, sendo que, algumas mais acessíveis em termos de custo para aquisição. A marca Canson (Figura 6), que comercializa o papel de mesmo nome, também conhecido como Debret, fabrica um produto de textura acentuada em relação aos outros tipos, e esta é, tanto tátil quanto visualmente, percebida de forma mais acentuada em uma das faces da folha. 
Como para o papel gramatura significa o peso de uma folha de $1 \mathrm{~m}^{2}$, expresso em gramas, a maior gramatura representa, independente do formato, uma folha de maior peso, um suporte mais rígido. As gramaturas mais usuais deste papel são: $140 \mathrm{~g} / \mathrm{m}^{2}, 180 \mathrm{~g} / \mathrm{m}^{2}$ e $200 \mathrm{~g} / \mathrm{m}^{2}$. Na necessidade de uma técnica mista que envolva o carvão e a aguada também a gramatura de $300 \mathrm{~g} / \mathrm{m}^{2}$ pode ser recomendada. $\mathrm{Na}$ imagem a seguir a gramatura do primeiro bloco é $180 \mathrm{~g} / \mathrm{m}^{2}$ e a do segundo $224 \mathrm{~g} / \mathrm{m}^{2}$.

"O papel Canson "C" à grainé é ideal para desenho, graças ao seu grão fino, que não é nem demasiado suave, nem demasiado acentuado, e permite criar efeitos de relevo e obter um resultado delicadamente equilibrado." (CANSON, 2019, p. 01). O fabricante apresenta para este produto três opções de gramatura: $125 \mathrm{~m}^{2} \mathrm{~g} /, 180 \mathrm{~g} / \mathrm{m}^{2}$ e $224 \mathrm{~g} / \mathrm{m}^{2}$.

Figura 6: Papel Canson
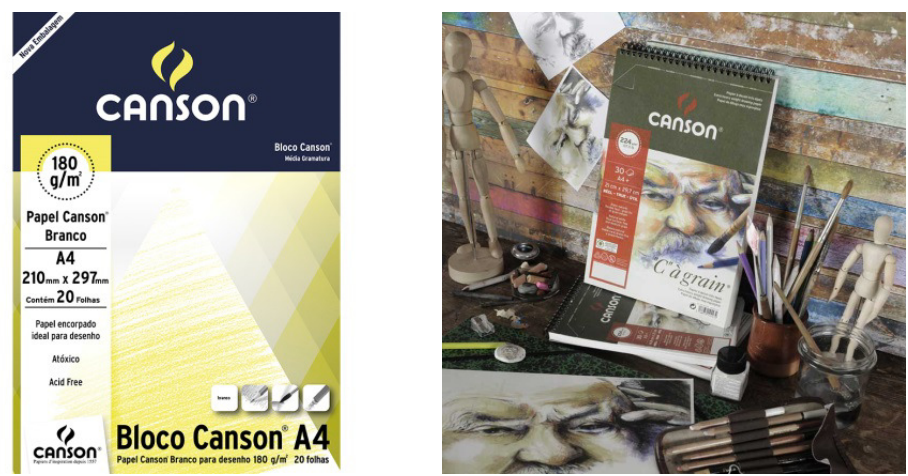

Fonte: http://pt.canson.com/marca (2019)

0 papel Ingres, fabricado especialmente para carvão, pode ser empregado para lápis, pastel e vários outros materiais de desenho. "0 papel Canson Guarro Ingres é um papel verjurado, de cor branca natural, com rebordos naturais em dois lados e marca de água. Contém 30\% de algodão, que lhe confere um tacto esponjoso." (CANSON, 2019, p. 01). Comercializado em folhas avulsas, de $50 \times 70 \mathrm{~cm}$ e $70 \times 100 \mathrm{~cm}$, pode ser encontrado também em blocos de tamanho 32,5 x $46 \mathrm{~cm}$ ou $23 \times 32,5 \mathrm{~cm}$ (Figura 7).

Figura 7: Papel Ingres e papel Montval
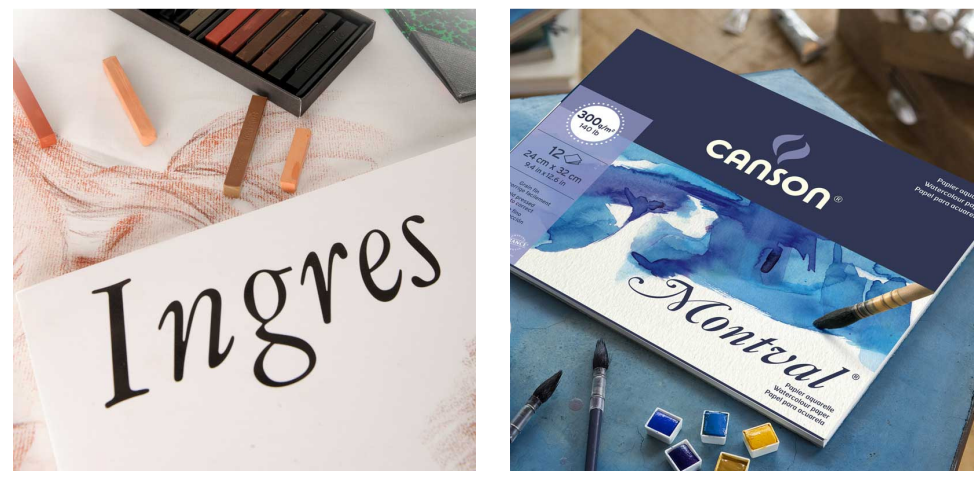

Fonte: http://pt.canson.com/marca (2019) 
A superfície áspera de certos tipos de papéis de aquarela fornece uma textura dinâmica aos traços; até mesmo as linhas acentuadamente pretas deixarão transparecer o branco do papel em alguns pontos. 0 papel de aquarela pode ser encontrado em folhas avulsas, rolos, blocos e álbuns como o tradicional papel Montval, que possui gramaturas de $185 \mathrm{~g} / \mathrm{m}^{2}, 200 \mathrm{~g} / \mathrm{m}^{2}$, $270 \mathrm{~g} / \mathrm{m}^{2}$ e $300 \mathrm{~g} / \mathrm{m}^{2}$ (Figura 7).

Conforme Marivc a escolha do papel é fundamental para o resultado do trabalho, pois o carvão comporta-se diferentemente em papéis com superfície mais lisa ou mais rugosa, nesses acentuando a sua textura. (MARIVC, 2010, p. 01).

0 papel deve também ser suficientemente sólido para resistir à borracha sem se desgastar. Para Diniz e Amaral outros papéis conhecidos, como o papel de arroz japonês ou papel manteiga também podem ser utilizados para desenhos a carvão (DINIZ; AMARAL, 2011, p. 13). 0 importante é experimentar o material em variadas superfícies como a dos painéis de ilustração, dando preferência aos que possuem uma textura macia - semelhante ao linho, e também a do papel de jornal para fazer esboços rápidos.

\subsection{Acessórios}

A maciez do carvão aumenta as chances de borrar acidentalmente o trabalho. Os borrões podem ser evitados a partir do cuidado de enrolar os bastões de carvão em papel. Outra precaução é ao terminar o desenho, aplicar uma de camada de spray fixador (figura 08).

Figura 8: Fixador para carvão e Limpa-tipos
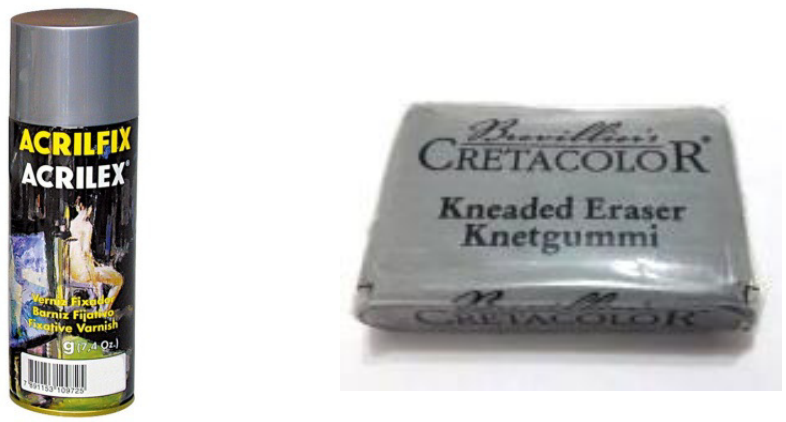

Fonte: https://www.papelero.com.br (2019)

O spray é útil principalmente para carvões muito macios, evitando que os riscos e as manchas se desprendam da superfície de desenho. Os carvões mais duros tendem a aderir com mais firmeza ao papel, nesse caso o fixador não é essencial.

Um cuidado para que os bastões não quebrem ou esfarelem, é segurálos bem próximo a ponta que toca no papel. Outra atitude cautelosa com o 
material é guardar os bastões e lápis de carvão em recipientes com compartimentos separados.

A facilidade com que o carvão borra o papel leva a muitos iniciantes a se excederem na utilização dos esfumados - que nem sempre são adequados ao motivo. 0 acessório conhecido como esfuminho de papel tem como objetivo esfumar o carvão. Conforme Ferrari para sua utilização recomendase a associação com um lenço de papel para limpar áreas insatisfatórias do desenho, ou para espalhar o tom suave sob uma grande área (FERRARI, 1985, p. 406). É fundamental lembrar de que alguns temas podem ser retratados de maneira mais expressiva por meio de uma variedade de traços. As áreas iluminadas podem ser produzidas com uma borracha mole ou com limpatipos (Figura 9). Além do fixador e do limpa-tipos o estilete é um acessório muito útil para apontar um carvão em bastão fino ou para lixar os bastões grossos. Um objeto qualquer duro torna-se um acessório para a quebra de um bastão de carvão com o objetivo de obter carvão em pó.

Marivc cita e que é possível apagar o carvão com a borracha miolo de pão (nome popular do limpa-tipos), com borrachas apropriadas (por exemplo: PVC) ou mesmo com um pano macio (MARIVC, 2010, p. 01).

\subsection{Técnicas}

Segundo Ferrari esfumar com carvão é um trabalho fácil e agradável. Por essa razão muitos artistas não conseguem resistir à tentação de esfumar e se limitam a esta técnica para obter os tons em seus trabalhos (FERRARI, 1985, p. 1167).

As possibilidades oferecidas para esfumar o carvão se diversificam da mesma forma em que se diferenciam as bases do desenho, ou seja, a gramatura e a rugosidade do papel utilizado para a ilustração. Fazendo o uso de uma folha lisa, obtêm-se gradações suaves que pouco revelam a textura da superfície. A maneira como a técnica é aplicada, leva a resultados distintos: valor (tons) - ao esfumar totalmente cada traço (Figura 9), ou mista (tons e traços), esfumando parcialmente o traçado (Figura 10). Por sua vez, a utilização de papel de maior aspereza é desafiante para o artista, visto que a gradação dos tons alcançada apresenta maior irregularidade. 
Figura 9: Modelagem com Tons
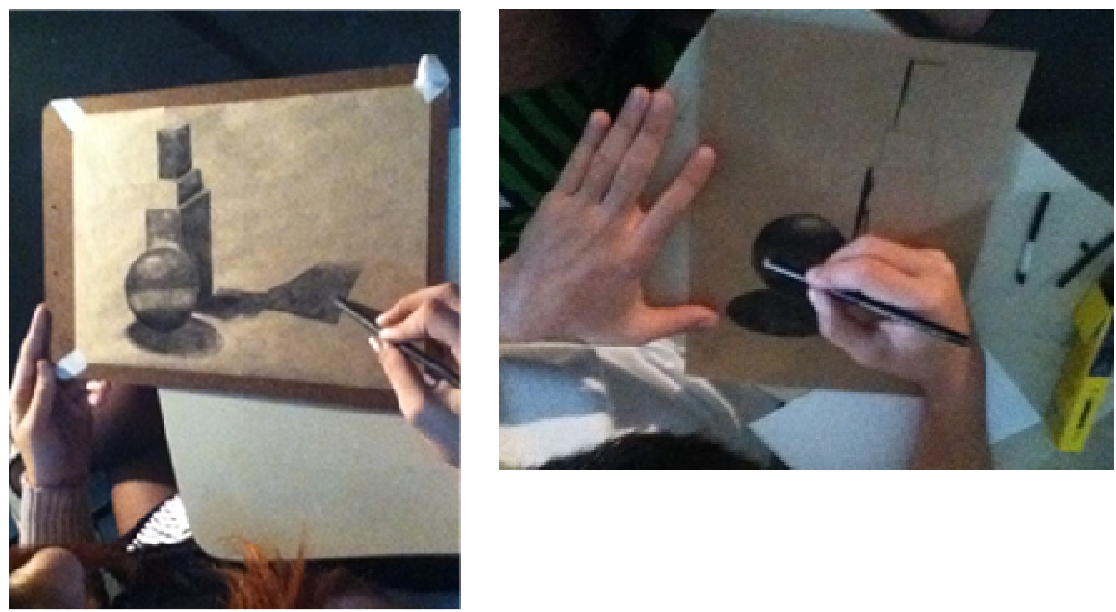

Fonte: DINIZ ; AMARAL (2011).

Embora desenhos esfumaçados cheguem a bons resultados fazer desenhos baseados em traços no carvão é uma maneira de praticar a técnica do grafismo, ou tom de linhas com um material que exigirá mais do desenhista pela variação da espessura da ponta. 0 desenho de Amaral, Figura 10, é um exemplo desta técnica.

Figura 10: Modelagem com Tons e traços

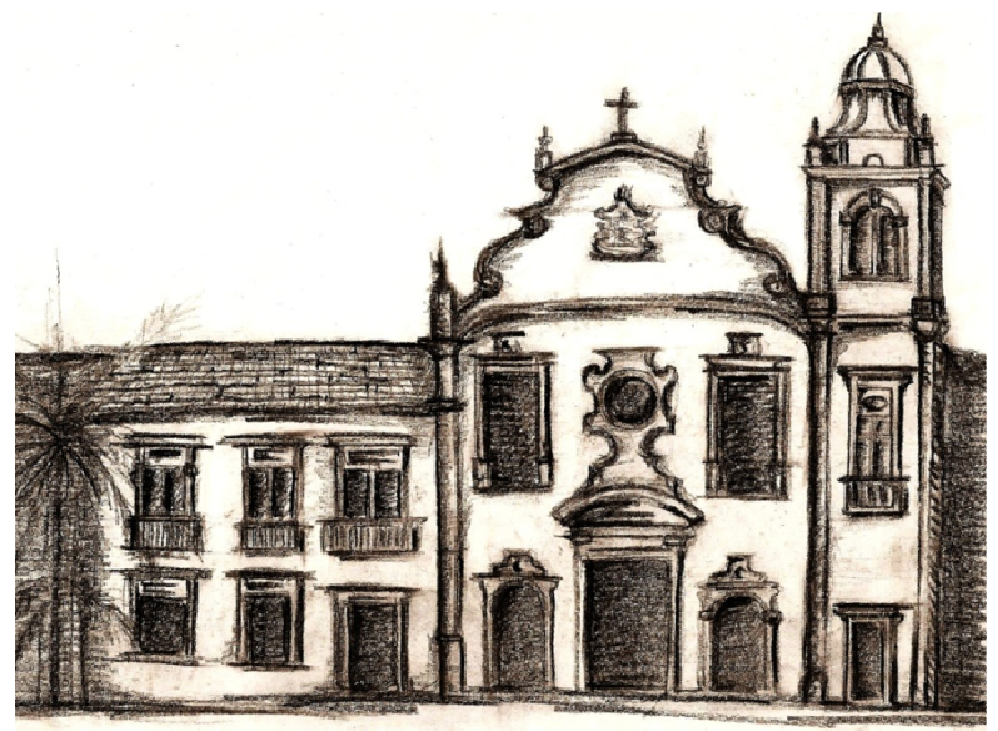

Fonte: DINIZ; AMARAL (2011).

De acordo com Ferrari as técnicas para desenho a carvão podem basear-se em traços, em fusão de tons ou no contorno gestual (FERRARI, 1985, p. 408). 
Figura 11: Modelagem com Lápis carvão e carvão em barra

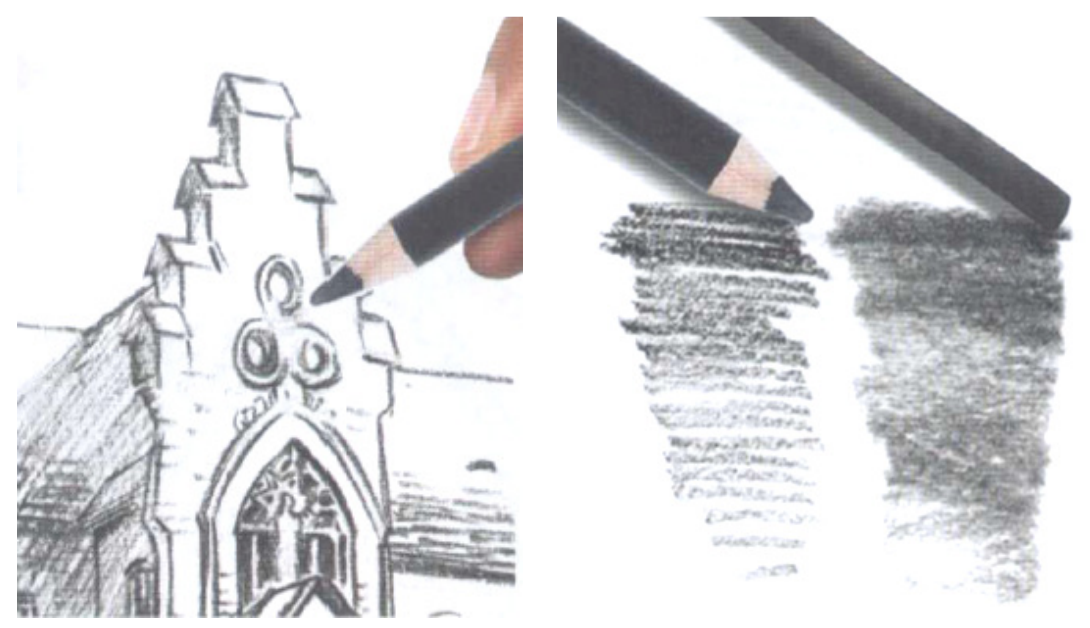

Fonte: COUTO, (2017).

A obra de Mozart Couto, um clássico para a expressão gráfica no Brasil, apresenta um capítulo dedicado ao carvão. A Figura 11 exemplifica no desenho de Couto a técnica utilizada por Amaral na Figura 10. Para Couto o lápis carvão pode ser utilizado para desenhos com detalhes por sua ponta ser mais firme. Outra vantagem é que se fixa mais no papel e o trabalho pode ser realizado sem a necessidade de usar fixador entre uma etapa e outra (COUTO, 2017, p. 47). Nesta figura também é possível observar a diferença entre o traçado do lápis e do carvão em barra, o primeiro mais intenso que o segundo.

Ferrari corrobora com Couto, para desenhar em áreas pequenas, é sempre mais fácil usar lápis carvão ao invés de bastões (FERRARI, 1985, p. 1086). 0 autor sugere exercícios, passo a passo, para experimentação dos diversos tipos de carvão com as técnicas dos tons e dos traços e aplicação de esfuminho.

Na figura 12, em um processo comparativo entre duas práticas de desenho, é notável a real diferença entre os resultados do traçado a carvão (à esquerda) e a representação a grafite 6B (à direita).

Figura 12: Desenho a Carvão e Desenho a Grafite
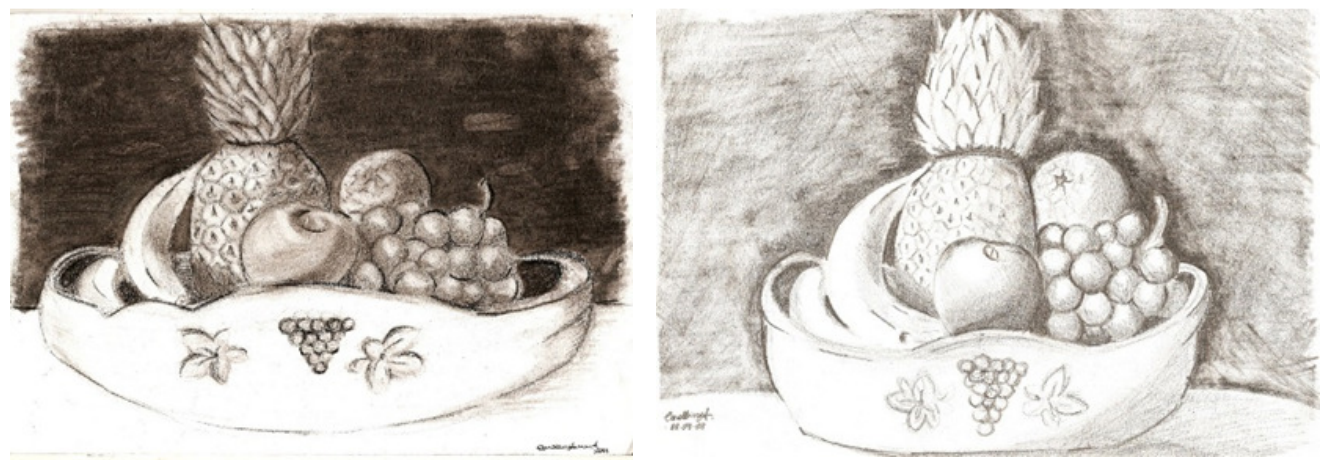

Fonte: DINIZ; AMARAL (2011). 
O carvão ainda permite a inversão da prática tradicional do desenho, o traçado na superfície branca. Por conta da sua maciez e fácil distribuição no papel, a possibilidade de criar o desenho a partir do processo de apagar o pó do carvão é algo que poucas ferramentas são capazes de proporcionar. Para tal técnica, o uso de borracha ou limpa-tipos são ideais. 0 contraste oferecido ressalta a sensação de "luminosidade" em meio ao vasto negro presente na folha. 0 carvão expressa com eficácia o jogo de luzes e sombras, as formas e os volumes, dando mais profundidade e valorizando o desenho.

\section{CONSIDERAÇÕES FINAIS}

Adaptado ao seu "restrito" uso nas representações gráficas, o carvão é sempre empregado com a finalidade de causar estímulo e sensibilidade. Por isso, seu uso deve ser planejado no sentido do melhor aproveitamento do material.

A análise e a investigação realizada no presente artigo visaram colaborar para a desmistificação do material com relação à dificuldade do uso e da pouca aplicabilidade. O carvão continua sendo necessário para "soltar" os primeiros traços e dar mais liberdade às representações.

Menos usual que os esfumaçados, a técnica de linhas ou técnica do grafismo ou ainda tom de linhas dá identidade ao autor à medida que gera traços marcantes em contraste com o fundo e que podem trazer o caráter dinâmico do croqui e dar fluidez aos esboços a carvão. Logo, o material é adaptável a diversas técnicas e indicado para muitos fins.

Apesar do impacto ambiental, considera-se que a quantidade de bastões de carvão produzidos para o desenho e pintura, não aumentam sensivelmente esta conta se comparada ao seu uso em escala industrial e, portanto, deve ser mantido.

O carvão ainda é utilizado como produção artística, expressiva e como fonte didática.

\section{REFERÊNCIAS BIBLIOGRÁFICAS}

BRITO, José Otávio. Princípios de produção e utilização de carvão vegetal de madeira. Notas de Aula, Departamento de Ciências Florestais / Escola Superior de Agricultura "Luiz de Queiroz", USO, Piracicaba, SP, Brasil, 1990.

CANSON. Papiers d'inspirationsince 1557. Disponível em: <http://pt.canson.com/marca>. Acesso em: 23 abr. 2011

CARVALHO, Sônia de Fátima Elias Mariano. A dialogia estética em Vicent Van Gogh. M. Sc., PPGEL/ UFU, Uberlândia, MG, Brasil, 2009.

COUTO, Mozart. Curso Técnico de Desenho. São Paulo: Editora Escala, 2017.

DINIZ, Luciana Nemer; AMARAL, Carolline. Estudo do carvão e sua aplicação na expressão. Monitoria, TAR/EAU, UFF, Niterói, RJ, Brasil, 2011. 
FARIA, Caroline. Mineração de carvão no Brasil. Infoescola - navegando e Aprendendo, 2006. Disponível em <https:// https://www.infoescola.com>. Acesso em 22 abr. 2019.

FERRARI, Vera Rodrigues Caetano. Carvão: material e técnicas. Rio de Janeiro: Rio Gráfica Editora, 1985.

FREITAS, Eduardo de. Carvão Vegetal. Disponível em <https://www.brasilescola.uol.com.br>. Acesso em 22 abr. 2019.

FRENHI, Ane. Desenho Artístico: técnica carvão. Disponível em: <https://www.entreculturas.com.br>. Acesso em: 22 out. 2011.

GONÇALVES, Rainer. A povoação das Américas. Disponível em: <https://www.historiadomundo.com.br)>. Acesso em: 22 abr. 2011.

GOUVEIA, Magaly. Desenho a Carvão: a técnica clássica de desenho. Disponível em: <https://www.amopintar.com>. Acesso em: 22 mar. 2019.

MARIVC. Desenhando ideias. Disponível em: <https://sketchingideas.wordpress.com>. Acesso em: 22 mar. 2010.

RIO GRANDE DO SUL. Minas e Energia. Desenvolvimento do carvão e do gás de carvão. Disponível em: <https://minasenergia.rs.gov.br>. Acesso em: 20 mar. 2019.

OHNO, Frederico. Corot. Disponível em: <https://www.pinterest.es>. Acesso em: 12 fev. 2019.

SAN FRANCISCO. Vincent Van Gogh. Disponível em: <https://www.portalsaofrancisco.com.br >. Acesso em: 19 mar. 2019.

UNIVERSIDADE FEDERAL DE RORAIMA. Período Carbonífero. Disponível em: <http:wwwhttp://ufrr.br/lapa>. Acesso em: 23 abr. 2019.

UNIVERSIDADE DE SÃO PAULO. Carvão Mineral. Disponível em: <http://www.cepa.if.usp.br >. Acesso em: 24 mar. 2019.

\section{AGRADECIMENTOS}

Agradecemos ao CNPq a bolsa de Iniciação Científica de Philipe Cantreva.

Agradecemos a Universidade Federal Fluminense à bolsa de Monitoria de Carolline Amaral. 